\title{
Anatomical and Biochemical Traits Related to Blue Leaf Coloration of Selaginella uncinata
}

\author{
Lin Li, ${ }^{1}$ Lulu Yang, ${ }^{2}$ Aihua Qin, ${ }^{2}$ Fangyi Jiang, ${ }^{2}$ Limei Chen, ${ }^{2}$ and Rongyan Deng $\mathbb{D}^{2}$ \\ ${ }^{1}$ College of Architectural Arts, Guangxi Arts University, Nanning 530007, China \\ ${ }^{2}$ Forestry College, Guangxi University, Nanning 530004, China \\ Correspondence should be addressed to Rongyan Deng; dengrongyan@gxu.edu.cn
}

Received 9 November 2021; Revised 16 December 2021; Accepted 27 January 2022; Published 24 February 2022

Academic Editor: Kalidoss Rajakani

Copyright $\odot 2022$ Lin Li et al. This is an open access article distributed under the Creative Commons Attribution License, which permits unrestricted use, distribution, and reproduction in any medium, provided the original work is properly cited.

Selaginella uncinata shows particularly rare blue leaves. Previous research has shown that structural interference by the cell wall of adaxial epidermal cells imparts blue coloration in leaves of $S$. uncinata; the objective of this study was to see whether anthocyanins might additionally contribute to this color, as changes in $\mathrm{pH}$, and conjugation with metals and other flavonoids is also known to result in blue coloration in plants. We compared anatomical and biochemical traits of shade-grown (blue) S. uncinata leaves to high light (red) leaves of the same species and also to a non-blue (green) leaves of a congeneric S. kraussiana. By examining the anatomical structure, we found that the shape of adaxial epidermis of $S$. uncinata leaves was convex or lens-shaped on the lateral view and irregular circles with smooth embossment on the top view. These features were different from those of the abaxial and adaxial epidermis of $S$. kraussiana. We suspect that these structures increase the proportion of incident light entering the cell, deepening the leaf color, and therefore may be related to blue leaf color in S. uncinata. By examining biochemical traits, we found little difference in leaf $\mathrm{pH}$ value among the leaf types; all leaves contained several metal ions such as $\mathrm{Mg}$, Fe, $\mathrm{Mn}$, and copigments such as flavones. However, because there was no anthocyanin in blue S. uncinata leaves, we concluded that blue coloration in $S$. uncinata leaves is not caused by the three hypotheses of blue coloration: alkalization of the vacuole $\mathrm{pH}$, metal chelation, or copigmentation with anthocyanins, but it may be related to the shape of the leaf adaxial epidermis.

\section{Introduction}

Colorful leaves are attractive features that characterize ornamental plants. Red, purple, yellow, and variegated leaves are common, whereas blue leaves are particularly rare. Selaginella uncinata, a fern species that is adapted to the shaded conditions, is such a blue leaf plant. It has a blue upper and green lower surface. There have been some reports related to $S$. uncinata focusing on structural anatomy [1], developmental anatomy [2], cell genetics [3], chloroplast genome [4-6], and chemicals and medicine [7-13]. Our previous research showed that the leaf color of $S$. uncinata appears normally blue in the shade, while it changes to red under full light exposure [14], and this color change under high light corresponded with a reduction in chlorophyll and anthocyanin and an increase in carotenoids, resulting in a dominant orange color. Based on the transcriptome sequencing and quantitative real-time polymerase chain reaction (qRT-PCR) analysis, we concluded that the primary pathway of pigment metabolism in S. uncinata may be the chlorophyll metabolism pathway rather than the anthocyanin biosynthesis pathway [15]. According to the research of leaf coloration mechanism, leaf coloration in plants can be due to either pigments or structural coloration. These two groups differ in their appearance-pigmented colors look the same from all angles, while structural colors appear with different hues when viewed from different angles, a unique attribute of structural color called iridescence [16].

There have been very few studies on the production of blue leaves. Hébant and Lee [1] found that the iridescent blue color of S. uncinata and S. willdenowii is caused by thin-film interference (a physical effect). In other blue iridescent plants, the iridescent ultrastructural basis is relevant to their adaxial epidermis, but they are different in detail. In Diplazium 
tomentosum, Lindsaea lucida, and Danaea nodosa, the iridescent ultrastructure is that in the uppermost cell walls of the adaxial epidermis, the arrangement of multiple layers of cellulose microfibrils is helicoidal $[17,18]$. In Begonia pavonina, Phyllagathis rotundifolia, and Elaeocarpus angustifolius, blue coloration is due to the parallel lamellae in specialized plastids (iridoplasts) adjacent to the abaxial wall of the adaxial epidermis $[18,19]$, while in Trichomanes elegans, it results from the remarkably uniform thickness and arrangement of grana in specialized chloroplasts adjacent to the adaxial wall of the adaxial epidermis [17]. In these studies, it was not possible to extract blue pigment from the study material, such that in all cases, blue iridescence was considered to be a structural color.

However, according to studies of blue flowers, $\mathrm{pH}$ in the vacuole [20-22], metal chelation [23], and copigmentation $[24,25]$ may also be related to blue coloration. It seems clear that blue leaves in $S$. uncinata have a structural mechanism, but whether it is also affected by any or all of these three factors remains unknown. In our previous study, we detected low content of anthocyanins in S. uncinata [14]. The objective of this study was to further investigate the possibility that anthocyanins may contribute to blue coloration in $S$. uncinata, by examining leaf $\mathrm{pH}$, metal ions, and pigment composition, in addition to anatomical structure.

\section{Material and Methods}

2.1. Plant Material. We conducted tests on three leaf types: blue $S$. uncinata leaves grown under a sunshade net (light intensity: 65-105 umol m $\mathrm{m}^{-2} \mathrm{~s}^{-1}$ ), green S. kraussiana leaves grown under the same conditions, and red S. uncinata leaves grown in full exposure (light intensity: 500-520 umol $\mathrm{m}^{-2} \mathrm{~s}^{-1}$ ) [14]. There were 6 POTS for each leaf type and 3 replicates for a total of 54 POTS. All plants were 6 months old, given normal water and fertilizer management, and cultivated in the nursery of the Forestry College, Guangxi University, Nanning, China. Mature normal leaves were selected randomly in different directions from various individuals when sampling.

2.2. Methods. We compared observations within species (blue and red S. uncinata leaves) and between species (blue S. uncinata and green S. kraussiana leaves). The traits examined included morphology, color parameters, leaf paraffin transverse sections, freehand sections, and scanning electron microscopy (SEM) photomicrographs to determine the structural mechanism. We also compared reported leaf $\mathrm{pH}$ values, and metal ion, anthocyanin, and flavonoid content to examine the physiological and biochemical mechanisms related to blue coloration.

\subsection{Anatomical and Morphological Traits}

2.3.1. Morphological Traits and Leaf Color Parameters. Morphological observations and measurements included leaf type, leaf texture, leaf color on the adaxial and abaxial sides, leaf size, and leaf thickness. The procedure is repeated 6 times, and the results are averaged.
Fresh leaves are taken, and leaf color in the middle of the upper epidermis was measured by Royal Horticultural Society Colour Chart (RHSCC) and a General Colorimeter (NR10QC, 3nh, Shenzhen). In a daylight condition, lightness $\left(L^{*}\right)$ and two chromatic components $a^{*}$ and $b^{*}$ of the CIEL $^{*} a^{*} b^{*}$ color coordinate were measured. Based on the equations: $C^{*}=\left(a^{* 2}+b^{* 2}\right)^{1 / 2}$ and $h=\arctan \left(b^{*} / a^{*}\right)$, chroma $\left(C^{*}\right)$ and hue angle $(h)$ were calculated. The procedure is repeated 5 times, and the results are averaged.

\subsubsection{Microscopic Observation of Leaf Transverse Sections.} The transverse sections of leaves were prepared according to $\mathrm{Li}$ [26]. Leaves were collected and fixed in a formalin-acetic acid-alcohol (FAA; absolute ethyl alcohol: glacial acetic acid, $3: 1$ ) solution for $30 \mathrm{~min}$; fixed samples were washed three times in $50 \%$ ethanol and dehydrated through a series of ethanol concentrations: 60\% (30 min), 70\% (30 min), 85\% (30 $\mathrm{min}$ ), $95 \%$ (5 min), and 100\% (5 min, twice). Ethanol in dehydrated samples was then replaced with xylol and paraffin, and samples were embedded and cut into sections of 8-14 $\mu \mathrm{m}$ thickness using a fully motorized rotary microtome (Leica RM2245, Germany). The sections were stained with Safranin Fast Green, washed with 50\% ethanol, and then observed with a digital microscope $(\times 10)$ (Nikon Eclipse E100, Japan).

\subsubsection{Microscopic Observation of Leaf Epidermal Cells.} Freehand sections were prepared for leaf shape observations. We rinsed $1.5 \times 2 \mathrm{~cm}$ leaf samples with distilled water, put them into a $1: 1$ solution of glacial acetic acid and $30 \%$ peroxide water, and then placed them in a $60^{\circ} \mathrm{C}$ incubator for 2-3 h. The samples were rinsed with distilled water, and peels (at least $2 \mathrm{~mm}$ long) of the upper and lower surfaces were made with fine-tipped tweezers from the central area of a single leaf and mounted in water, stained with Safranin for 30-60 s, washed, and observed with a digital microscope (Nikon Eclipse E100) [27].

2.3.4. Scanning Electron Microscopy. Leaf epidermal threedimensional structure was observed by SEM (Hitachi, S-3400N, Japan). $1.5 \times 2 \mathrm{~cm}$ samples from each of the three samples were cut, respectively, from the middle of each leaf and fixed with $2.5 \%$ glutaraldehyde solution for $2 \mathrm{~h}$ at room temperature, rinsed with $0.1 \mathrm{~mol} \mathrm{~L}^{-1}$ phosphate saline buffer, and dehydrated through increasing alcohol series, and then, the alcohol was replaced with isoamyl acetate. The samples were dried naturally, cut into appropriate sizes, and coated using a sputter coater. They were subsequently observed and photographed using SEM [28].

\subsection{Physiological and Biochemical Traits}

2.4.1. Measurement of Leaf $p H$. The three samples were collected and rinsed, and $5 \mathrm{~g}$ of leaves was weighed and cut into pieces. We then added $50 \mathrm{ml}$ distilled water, vibrated the samples for $10 \mathrm{~min}$ after soaking for $12 \mathrm{~h}$, and measured the $\mathrm{pH}$ of the solution at $30^{\circ} \mathrm{C}$ using a $\mathrm{pH}$ meter (PHS-25, 
Hongyi, Shanghai) [29]. The procedure is repeated 3 times, and the results are averaged.

2.4.2. Leaf Metal Ion Measurements. Dried leaves were ground into a fine powder, and a $0.6 \mathrm{~g}$ sample of dried material was digested in $5 \mathrm{ml}$ of concentrated $\mathrm{HNO}_{3}$ and $1 \mathrm{ml}$ of $\mathrm{H}_{2} \mathrm{O}_{2}$, followed by the treatment in a high-performance microwave digestion unit (CEM, Mars, Matthews, NC, USA). Settings used were as follows: time (minutes)/ power (watts)/temperature $\left({ }^{\circ} \mathrm{C}\right): 5 / 1,200 / 120,10 / 1,200 / 160$, and 20/1,200/180. After complete digestion and acid removal, the samples were diluted with ultrapure water for measurement. The procedure is repeated 3 times, and the results are averaged. Sample solutions were analyzed for elements by ICP-MS (NexION 350X, PerkinElmer, Waltham, MA, USA). The parameters for analysis were as follows: plasma power: $1,400 \mathrm{~W}$, plasma flow: $181 / \mathrm{min}$, auxiliary flow: $1.8 \mathrm{l} / \mathrm{min}$, and sampling depth: $7.5 \mathrm{~mm}$ [30].

2.4.3. Anthocyanin Analysis. Only blue leaf samples were analyzed for anthocyanin components using ultra-performance liquid chromatography (UPLC). The methods of extraction were as previously described [31] with some modifications. Anthocyanins were extracted from $0.5 \mathrm{~g}$ freeze-dried leaf powder from blue leaves in $25 \mathrm{ml}$ of $2 \%$ formic acid/methyl alcohol for $24 \mathrm{~h}$ at $4^{\circ} \mathrm{C}$. The supernatant was removed and stored under the same conditions. The extraction was repeated once. These two extractions were merged and subjected to rotary evaporation at $30^{\circ} \mathrm{C}$ until the anthocyanins were dry. We then added a moderate amount of $2 \%$ formic acid solution to dissolve the residue and ethyl acetate to extract the anthocyanins in the aqueous phase.

A $20 \mu \mathrm{L}$ sample was quantified by UPLC-triple-time-offlight/mass spectrometry (TOF/MS) (Acquity ${ }^{\mathrm{TM}}$ Ultra, Waters, Milford, MA, USA) at a flow rate of $0.8 \mathrm{ml} / \mathrm{min}$ and a column temperature of $30^{\circ} \mathrm{C}$ using a $4.6 \times 100 \mathrm{~mm}$ column of $\mathrm{C} 18$ and a linear gradient of solvent A ( $0.1 \%$ formic acid/ water $(\mathrm{v} / \mathrm{v}))$ in solvent B (acetonitrile) for $30 \mathrm{~min}$. The detection was performed by absorption at $520 \mathrm{~nm}$. The gradient settings were as follows: $0 \mathrm{~min}, 10 \% \mathrm{~B} ; 5 \mathrm{~min}, 10 \% \mathrm{~B}$; $20 \mathrm{~min}, 40 \% \mathrm{~B} ; 25 \mathrm{~min}, 100 \% \mathrm{~B}$; and $30 \mathrm{~min}, 10 \% \mathrm{~B}$.

2.4.4. Flavonoid Analysis. The extraction methods as previously described by Zhu et al. [27] were referenced with some modifications. Flavonoids were extracted from $1.0 \mathrm{~g}$ freeze-dried leaf powder from three $2 \%$ formic acid/methyl alcohol samples, after oscillation in ultrasonic cleaners for $20 \mathrm{~min}$ at $20^{\circ} \mathrm{C}$, and clarified by centrifugation at $12,235 \times \mathrm{g}$ for $10 \mathrm{~min}$. The supernatant was then collected. The extraction was repeated twice, and the total extraction volume was $25 \mathrm{ml}$. After the combined extraction was filtered with a $0.22 \mu \mathrm{m}$ nylon microporous filter, the solution was tested.

UPLC conditions are as follows: a $5 \mathrm{uL}$ sample was quantified by UPLC-Triple-TOF/MS (Acquity ${ }^{\mathrm{TM}}$ Ultra, Waters) at a flow rate of $0.8 \mathrm{ml} / \mathrm{min}$ and a column temperature of $30^{\circ} \mathrm{C}$ using a $4.6 \times 100 \mathrm{~mm}$ column of $\mathrm{C} 18$ and a linear gradient of solvent $\mathrm{A}(0.1 \%$ formic acid/water $(\mathrm{v} / \mathrm{v}))$ in solvent B $(0.1 \%$ formic acid/acetonitrile $(\mathrm{v} / \mathrm{v}))$ for $38 \mathrm{~min}$. The detection was performed by absorption at $280 \mathrm{~nm}$. The gradient settings were as follows: $0 \mathrm{~min}, 5 \% \mathrm{~B} ; 2 \mathrm{~min}, 5 \% \mathrm{~B}$; $25 \mathrm{~min}, 50 \% \mathrm{~B} ; 35 \mathrm{~min}, 95 \% \mathrm{~B} ; 37 \mathrm{~min}, 95 \% \mathrm{~B}$; and $38 \mathrm{~min}$, $5 \% \mathrm{~B}$.

MS was performed on an UPLC-Triple-TOF 5600 Plus System (AB Sciex, Framingham, MA, USA) equipped with an electrospray ionization source (ESI) system. The optimal MS conditions were as follows: scan range $\mathrm{m} / \mathrm{z}$ of $100-1500$. The experiment was conducted in negative ion mode, with a source voltage of $-4.5 \mathrm{kV}$ and source temperature of $550^{\circ} \mathrm{C}$. The pressure of both gas 1 (air) and gas 2 (air) was set to $50 \mathrm{psi}$. The pressure of curtain gas (N2) was set to $35 \mathrm{psi}$. The maximum allowed error was set to $\pm 2 \mathrm{ppm}$. The collision energy was $40 \mathrm{~V}$, with a collision energy spread of $20 \mathrm{~V}$. Exact mass calibration was performed automatically before each analysis, employing the automated calibration delivery system.

\section{Results}

\subsection{Anatomical and Morphological Traits}

3.1.1. Morphological Traits and Leaf Color Parameters. Blue S. uncinata leaves were soft and thin; newly formed leaves were grass green. The adaxial side of mature leaves was glaucous, showing iridescence (Figure 1(a)), whereas the abaxial side was green (Figure 1(b)). Red S. uncinata leaves were hard and crisp; newly formed leaves were also grass green, and the adaxial and abaxial sides of the mature leaf were red (Figures 1(c) and 1(d)). S. kraussiana leaves were thick and soft; newly formed leaves and the adaxial and abaxial sides of mature leaves were all green (Figures 1(e) and $1(f))$.

The measurement data for the three samples are shown in Table 1. The results indicated that the thickness of red leaves was significantly greater than that of blue leaves, whereas the area of blue leaves was significantly greater than that of red leaves.

The color parameters for the three samples are shown in Table 2. The results indicated that their hue angles $(h)$ are all near $0^{\circ}$ and belong to the red-purple area. The chroma $\left(C^{*}\right)$ of blue leaves was significantly greater than that of red leaves.

Note: data analysis used Duncan's method, and the data of $L^{*} a^{*} b^{*}=$ mean value \pm standard deviation $(n=5)$; A and $B$ show the different significant differences at $P=0.05$ level in SNK test.

\subsubsection{Anatomical Structure of Leaf Transverse Section.} The anatomical structure was observed in leaf transverse sections by the paraffin section. The three leaf types shared some similar features: the epidermis is covered by the cuticle; between the upper epidermis and the lower epidermis are irregularly shaped mesophyll cells; and there is no obvious differentiation of palisade and spongy tissue in the mesophyll. There are large chloroplasts in the mesophyll cells; these are long, narrow, and moniliform distribution. Cell arrangement is loose, with large gaps between the cells, 


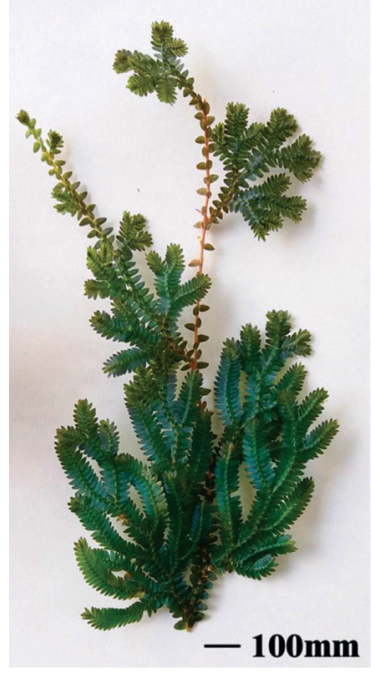

(a)

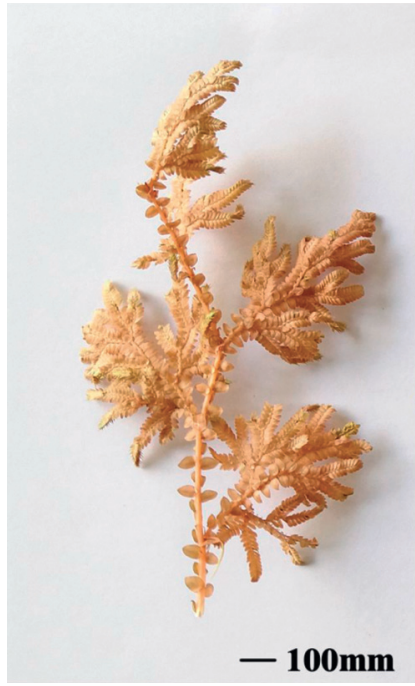

(d)

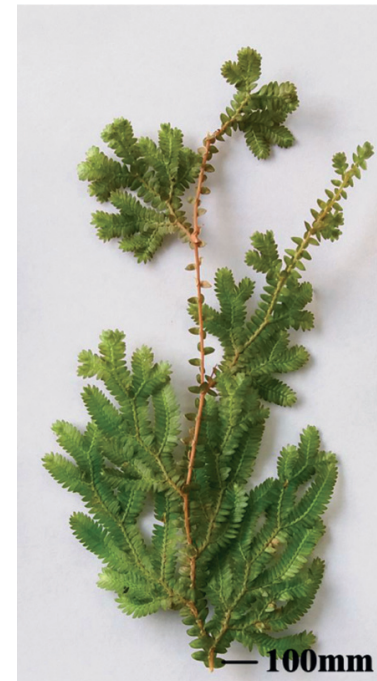

(b)

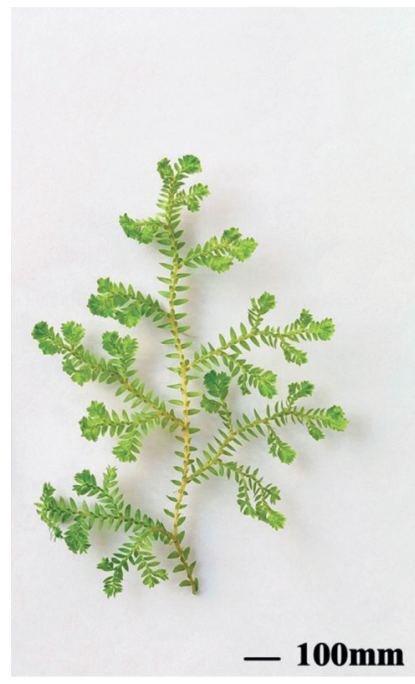

(e)

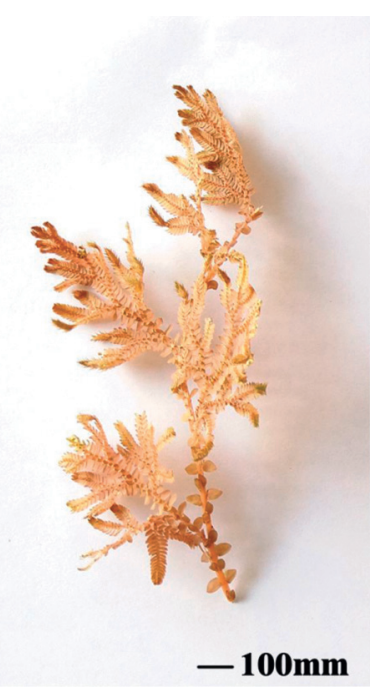

(c)

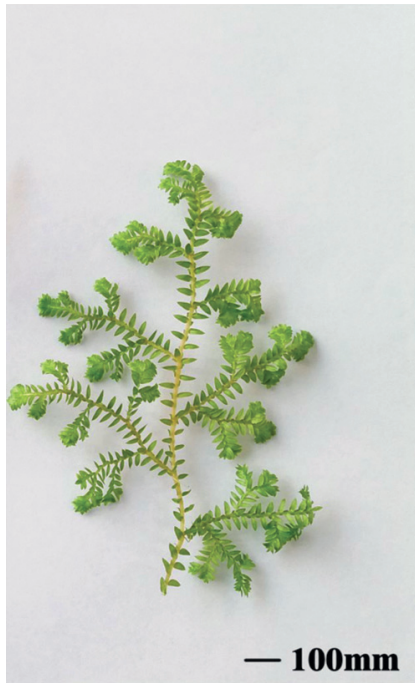

(f)

Figure 1: Appearance of the three leaf types. (a) Adaxial sides of blue Selaginella uncinata leaves; (b) abaxial sides of blue S. uncinata leaves; (c) adaxial sides of red S. uncinata leaves; (d) abaxial sides of red S. uncinata leaves; (e) adaxial sides of S. kraussiana leaves; and (f) abaxial sides of S. kraussiana.

TABLE 1: Morphological comparison of the three leaf types.

\begin{tabular}{|c|c|c|c|c|c|}
\hline \multirow{2}{*}{ Leaf type } & \multirow{2}{*}{ Leaf texture } & \multirow{2}{*}{ Leaf thickness $(\mu \mathrm{m})$} & \multicolumn{3}{|c|}{ Leaf area } \\
\hline & & & Length $(\mathrm{mm})$ & Width $(\mathrm{mm})$ & $\mathrm{LW}^{-1}$ \\
\hline Blue S. uncinata leaves & Soft and thin & $48.53 \pm 3.56 \mathrm{~B}$ & $3.25 \pm 0.61 \mathrm{C}$ & $1.73 \pm 0.44 \mathrm{C}$ & 1.9 \\
\hline Red S. uncinata leaves & Hard and crisp & $84.34 \pm 4.62 \mathrm{C}$ & $3.09 \pm 0.63 \mathrm{~A}$ & $1.53 \pm 0.27 \mathrm{~B}$ & 2.0 \\
\hline S. kraussiana leaves & Thick and soft & $35.73 \pm 3.05 \mathrm{~A}$ & $3.20 \pm 0.32 \mathrm{~B}$ & $1.37 \pm 0.34 \mathrm{~A}$ & 2.4 \\
\hline
\end{tabular}

Note: data analysis used Duncan's method, the data of leaf thickness, and length and width = mean value \pm standard deviation $(n=6) ; \mathrm{A}, \mathrm{B}$, and C show the different significant differences at $P=0.05$ level in SNK test.

TABLE 2: Color parameters of the three leaf types.

\begin{tabular}{|c|c|c|c|c|c|c|}
\hline Leaf type & RHSCC (A) & $L^{*}$ & $a^{*}$ & $b^{*}$ & $C^{*}$ & $\mathrm{~h} /{ }^{\circ}$ \\
\hline Blue S. uncinata leaves & 120 & $88.87 \pm 0.83 \mathrm{~B}$ & $-0.85 \pm 0.21 \mathrm{~A}$ & $-1.31 \pm 0.10 \mathrm{~A}$ & $1.57 \pm 0.19 \mathrm{~B}$ & $1.01 \pm 0.09 \mathrm{~A}$ \\
\hline Red S. uncinata leaves & 59 & $81.35 \pm 6.34 \mathrm{~A}$ & $0.00 \pm 0.35 B$ & $-0.46 \pm 0.73 \mathrm{~B}$ & $0.83 \pm 0.26 \mathrm{~A}$ & $0.69 \pm 1.27 \mathrm{~A}$ \\
\hline S. kraussiana leaves & 141 & $85.61 \pm 3.90 \mathrm{AB}$ & $-0.42 \pm 0.48 \mathrm{AB}$ & $-0.97 \pm 0.39 \mathrm{AB}$ & $1.09 \pm 0.53 \mathrm{AB}$ & $0.66 \pm 1.23 \mathrm{~A}$ \\
\hline
\end{tabular}


forming well-developed aeration tissue in the mesophyll cells.

The shapes of leaf adaxial and abaxial epidermal cells in blue and red S. uncinata were different from S. kraussiana. The shape of leaf adaxial and abaxial epidermal cells was different in blue leaves: the adaxial epidermis consisted of convex or lens-shaped cells, whereas the abaxial epidermis consisted of long cylindrical cells on the lateral view. In blue leaves, chloroplasts were distributed in the upper and lower epidermal cells, and in mesophyll cells, they were mainly at the bottom of the upper epidermal cells (Figure 2(a)). The shape of leaf adaxial and abaxial epidermal cells in red leaves was similar to that of blue leaves; however, the cells were much more closely aligned, and chloroplasts were significantly reduced (Figure 2(b)). The leaf adaxial and abaxial epidermal cells in S. kraussiana were long and cylindrical on the lateral view. Chloroplasts were distributed in the upper and lower epidermal and mesophyll cells, but primarily in the mesophyll cells (Figure 2(c)).

3.2. The Shape of Epidermal Cell. We used the freehand section to observe epidermal cells from the upper face and SEM photomicrographs to observe the three-dimensional shape of the epidermal cells. We found that the shapes of leaf adaxial and abaxial epidermal cells in blue $S$. uncinata were different: the adaxial epidermis was irregular circles, with smooth embossment, and by contrast, the abaxial epidermis was a long, wavy, irregular strip, with elongated embossment on the top view (Figure 3(e)). The shape of leaf adaxial and abaxial epidermal cells in red leaves was similar to that of blue leaves (Figure 3(f)). The leaf adaxial and abaxial epidermal cells in S. kraussiana were both shaped as irregular long strips, with elongated embossment on the top view (Figure 3(g)).

\subsection{Physiological and Biochemical Traits}

3.3.1. Leaf $\mathrm{pH}$. Leaf $\mathrm{pH}$ values were in the range of 4.5-5.0 (Table 3), in the order blue S. uncinata leaves $>$ red $S$. uncinata leaves $>S$. kraussiana leaves. The $\mathrm{pH}$ value of blue S. uncinata leaves was significantly greater than that of other two.

3.3.2. Leaf Metal Ion Content. Mg ions were very abundant in all three leaf types (>3000 mg/kg). The Ca, Mn, Fe, Zn, and $\mathrm{Al}$ ion contents were also relatively high $(55-1200 \mathrm{mg} / \mathrm{kg}$ ). There was little $\mathrm{Cu}$ ion content $(<9 \mathrm{mg} / \mathrm{kg})$. Cd ion content was the lowest, ranging from 0.03 to $0.04 \mathrm{mg} / \mathrm{kg}$ (Table 4).

3.3.3. Anthocyanin Analysis. The extract solution in blue $S$. uncinata leaves contained no anthocyanins (Figure 4). No anthocyanin ion peaks were observed through mass spectrometry. The result is in line with our conclusion that was previously published: the primary pathway of pigment metabolism in S. uncinata might not be the anthocyanin biosynthesis pathway, but rather the chlorophyll metabolism pathway [15].
3.3.4. Flavonoid Analysis. There was good flavonoid separation among the three leaf types (Figures 5-7). We compared the peaks on the chromatographic map and the results of the mass spectrogram, total ion flow diagram, and debris ion mass spectrum analysis to the SciFinder and Reaxys databases and finally inferred 15, 20, and 9 types of flavonoids in blue $S$. uncinata leaves, red S. uncinata leaves, and $S$. kraussiana leaves, respectively (Figure 8 and Table 5).

3.3.5. Comparison of Flavonoid Composition in the Three Leaf Types. There are 7 common compounds in the three leaf types: apigenin 6,8-di-C- $\alpha$-L-arabinopyranoside, amentoflavone, robustaflavone, 2,3-dihydrorobustaflavone, bilobetin, robustaflavone $4^{\prime}$-methyl ether, and $4^{\prime}, 7^{\prime \prime}$-di-Omethylamentoflavone.

We find that the vast majority of the flavonoids present (14 compounds) in blue and red leaves are similar; the component specific to blue leaves was genistein, which has an antioxidant effect. Components specific to red leaves were 6,8-C-diglucosylapigenin, apigenin 6,8-di-C- $\alpha$-L-arabinopyranoside, apigenin 6,8 -di-C- $\alpha$-L-arabinopyranoside isomeride, 3-O-methylamentoflavone, dihydrobilobetin, and dihydrorobustaflavone 4'-methyl ether. These components are likely to play an adaptive role in high light intensity $S$. uncinata environments.

The results show that most of the flavonoids $(7 \mathrm{com}$ pounds) in blue $S$. uncinata leaves and S. kraussiana leaves are similar. The components specific to blue leaves were 6-Carabinosyl-8-C-glucosylapigenin, genistin, genistein, $2^{\text {“ }} 3$ 3“dihydroamentoflavone, 2,3,2",3“-tetrahydroamentoflavone, 2,3-dihydroamentoflavone, 2,3,2",3"-tetrahydrorobustaflavo ne, and 7"-O-methyl-2,3,2“,3"-tetrahydrohinokiflavone. Amo ng these, genistin and genistein are isoflavones. The compo nents specific to $S$. kraussiana were 3-O-methylamentoflavone and robustaflavone 4'-methyl ether isomeride.

3.3.6. Comparison of Blue S. uncinata Leaf Flavonoid Composition with Published Values. Zheng et al. [9] identified seven types of flavonoids using high-performance liquid chromatography (HPLC), modern spectroscopy, and nuclear magnetic resonance (NMR). Four of these were consistent with our results: amentoflavone, 2", 3"-dihydroamentoflavon", 2,3,2",3"-tetrahydroamentoflavone, and 2,3-dihydroamentoflavone. Yiet al. [32] also identified 2,3dihydroamentoflavone. Of the five identified types of flavonoids detected by [33] through Sephadex LH-20, chromatography, UV, and MS, those in common with our findings were as follows: amentoflavone, robustaflavone, and 7"-Omethyl-2,3,2",3"-tetrahydrohinokiflavone. However, there was no common constituent between the studies of Wuet al. [34] and this study. In conclusion, flavonoids identified in blue $S$. uncinata leaves were similar to those found in previous studies; others were slightly different in structure.

\section{Discussion}

4.1. The Adaptability of Leaf Morphology and Anatomical Structure to Environmental Conditions. Leaf thickness is an 


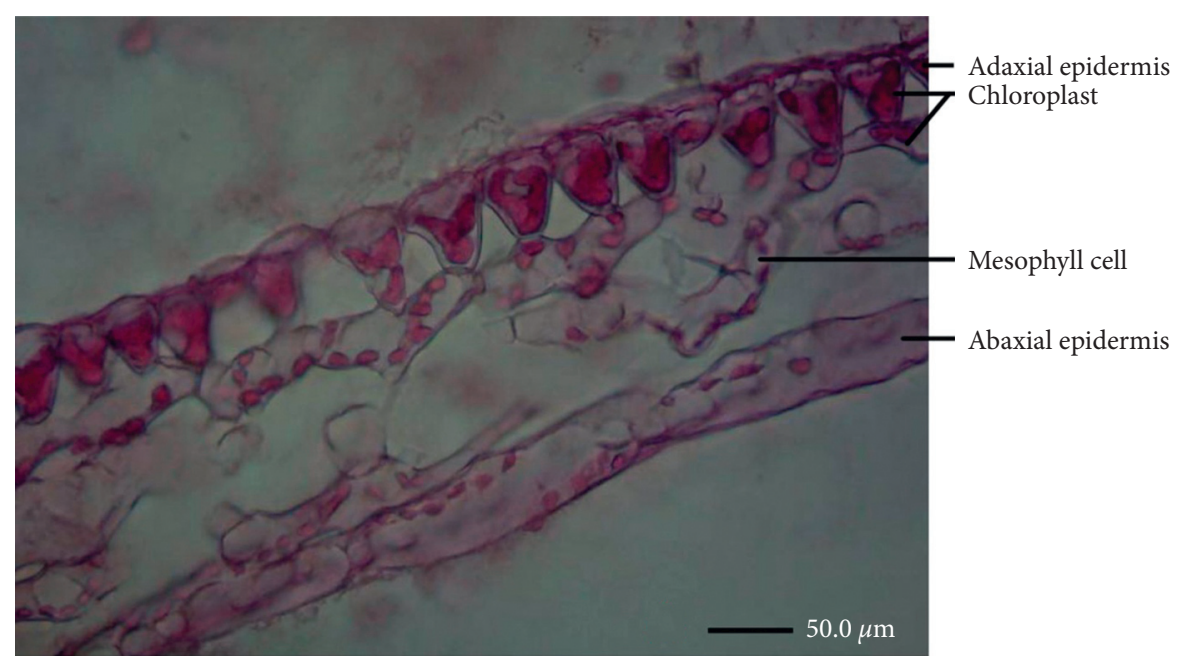

(a)

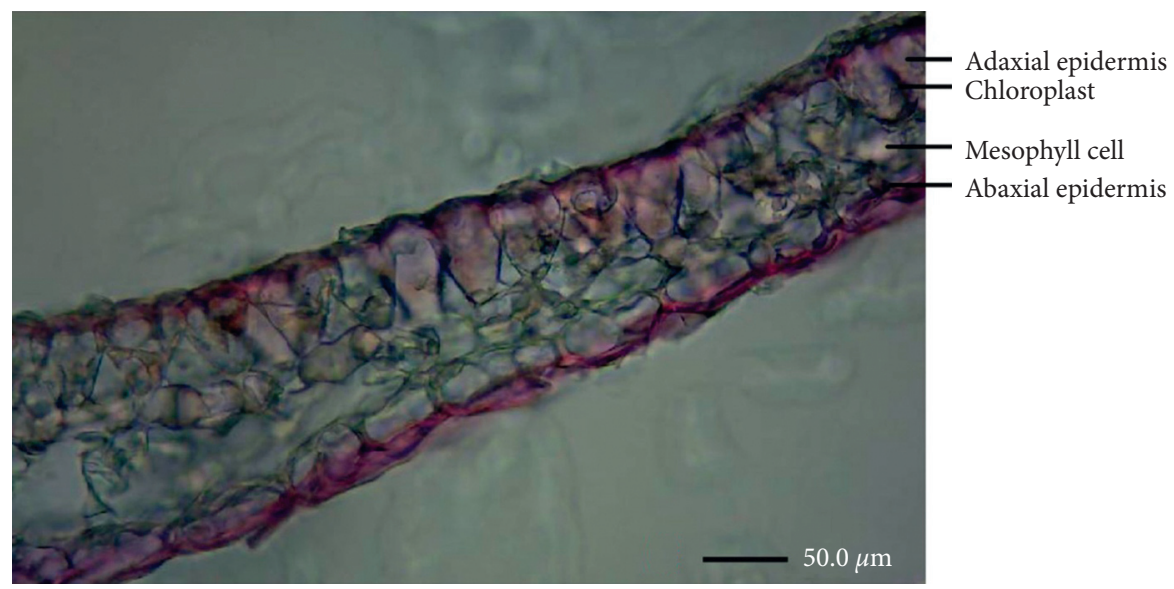

(b)

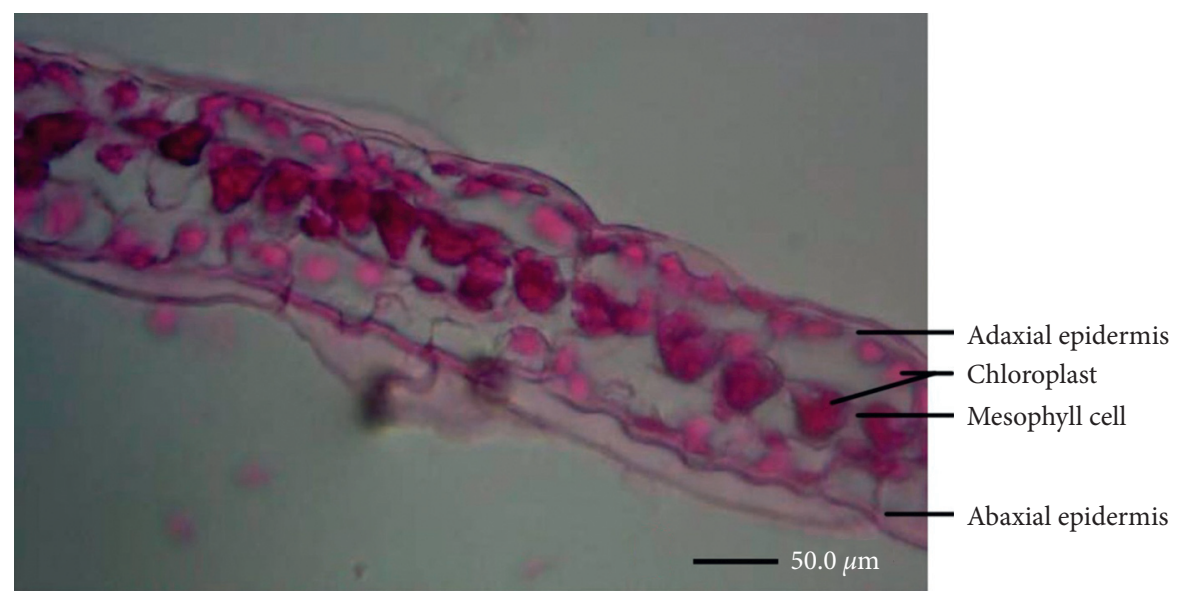

(c)

FiguRE 2: Leaf paraffin transverse sections of the three leaf types. (a) Blue S. uncinata leaf; (b) red S. uncinata leaf; and (c) S. kraussiana.

important indicator of plant shade tolerance. Thinner leaves make fern chloroplasts more fully capable of absorbing light energy; improving the photosynthetic efficiency of ferns; and making them better adapted to shaded environments [35]. Morphology traits and measurement data show that blue $S$. uncinata leaves, including increased leaf area and decreased leaf thickness, are adaptations to low-light environments and weak-light intensity.

Many researchers consider that shade-tolerant trees have a greater ability to change their leaf anatomical structure [36]. Leaf anatomical structure traits such as wax coating, shape of epidermal cells, epidermal thickness, and epidermal 


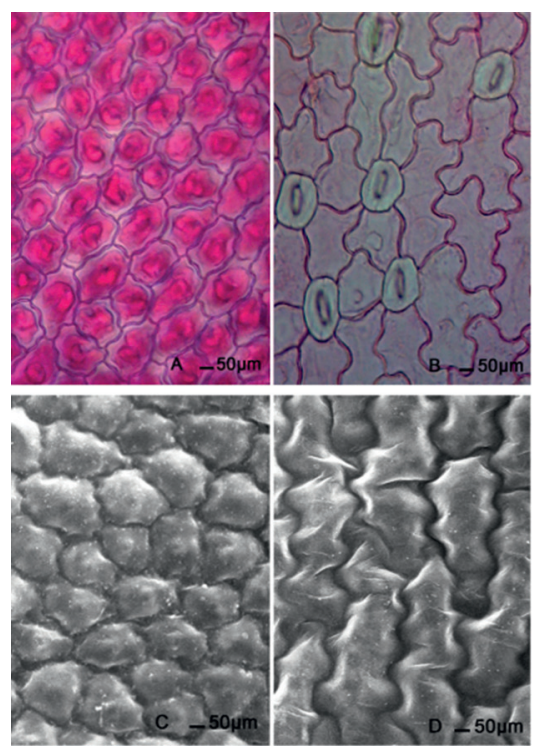

(E)
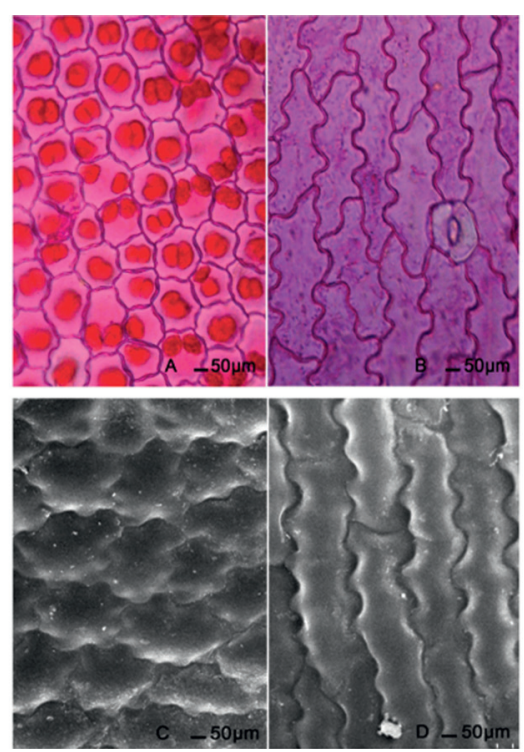

(E)
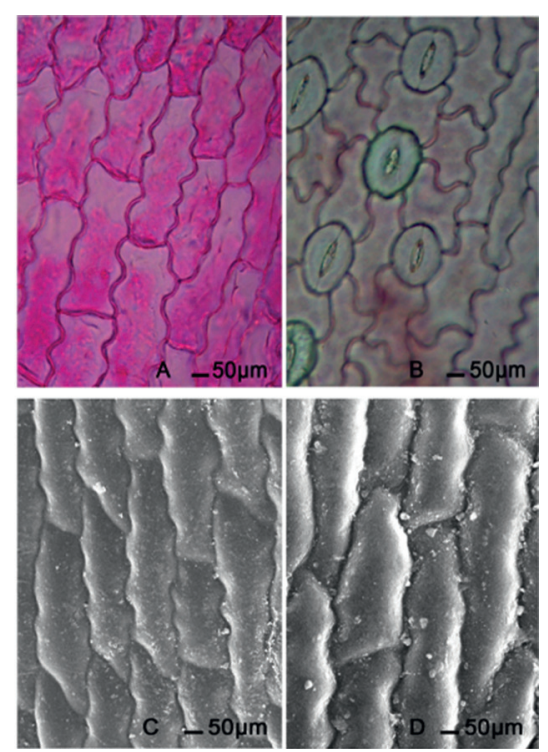

$(\mathrm{G})$

FIGURE 3: Leaf epidermal cell shape of the three leaf types. (a) Freehand section photomicrographs of adaxial epidermis; (b) freehand section photomicrographs of abaxial epidermis; (c) SEM photomicrographs of adaxial epidermis; (d) SEM photomicrographs of abaxial epidermis; (e) blue S. uncinata leaf; (f) red S. uncinata leaf; and (g) S. kraussiana.

TABLE 3: Leaf $\mathrm{pH}$ values for the three leaf types.

\begin{tabular}{lc}
\hline Leaf type & $\mathrm{pH}$ \\
\hline Blue $S$. uncinata leaves & $4.63 \pm 0.03 \mathrm{~B}$ \\
Red $S$. uncinata leaves & $4.55 \pm 0.01 \mathrm{~A}$ \\
S. kraussiana leaves & $4.52 \pm 0.01 \mathrm{~A}$ \\
\hline
\end{tabular}

Note: $\mathrm{pH}$ values are means \pm standard deviation $(n=3)$; A and B show the different significant differences at $P=0.05$ level in SNK test.

hair play an important role in light absorption, even determining the light use efficiency of the plant [37]. Deepshade plants change their morphology and physiology traits of cells and chloroplasts to fit the low-light conditions [38]. In the paraffin sections of the three leaf types, we observed no clear differentiation of the palisade and spongy tissues in the mesophyll, and mesophyll cells were irregularly distributed. This trait contributes to reducing projection loss of quantum light, allowing the plant to fully utilize limited light to carry out photosynthesis and accumulate organic matter, thus adapting to the shaded environment [35].

Previous research has shown that fern mesophyll cells possess more intercellular space, forming well-developed aeration tissue that can be used to store gases for photosynthesis and respiration, to make up for deficiencies in gas absorption, which is also an adaptation to a shaded environment [35]. The chloroplast is the main site of photosynthesis; in ferns, this structure appears long and narrow and is distributed as a moniliform, reducing the amount of photons penetrating the leaf and raising the utilization rate of quantum light in weak-light conditions, to improve the efficiency of leaf photosynthesis [35]. Plant chloroplasts typically exist in mesophyll cells, but through paraffin section observation, we found that chloroplasts in blue $S$. uncinata leaves exist mainly in epidermal cells and are larger.
This result is consistent with that of Hébant and Lee [1], who examined transverse leaf sections of $S$. uncinata by light microscopy, but is different from those of Sheue et al., and they found several chloroplasts in the mesophyll cells and the ventral epidermal cells, while only one single giant chloroplast (bizonoplast, BP) per dorsal epidermal cell [39]. The preferential localization of chloroplasts in the lower part of the epidermal cells in S. uncinata would allow more light to penetrate and reach mesophyll cells [39], which is an adaptation of plants to weak-light environments.

4.2. Effects of the Shape of Leaf Epidermal Cells on Blue Coloration in S. uncinata. The shape of petal epidermal cells has a great influence on the formation of flower color. Noda et al. [40] found that a conical shape in the epidermal cells of petal was believed to enhance light absorption and thus intensified its color, while the flat shape could reflect more incident light and thus lightened its color. Quintana et al. [41] found that in Anagallis, the epidermis contains anthocyanins, and most epidermal cells are flat, with domeshaped and conical cells in the outer layer. Mudalige et al. inspected the perianths of 34 Dendrobium Sw. species and hybrids to clarify the relevance of pigment distribution, the shape of upper epidermal cells, color intensity, perception, and visual texture [42]. Four types of epidermal cell shapes were identified in these Dendrobium flowers: flat, domeshaped, elongated dome-shaped, and papillate [42]. Yue [43] observed using SEM measurements that the epidermal cell shapes of 17 monocotyledon flowers could be grouped into five classes: conical, flat, oval, strip-shaped, and irregular mosaic. That study suggested that convex epidermal cells increased the refraction of light, making petal color appear deeper, and that bulging cells appeared to be more 
TABLE 4: Metal ion contents of the three leaf types.

\begin{tabular}{lcccccccc}
\hline Sample name & & & \multicolumn{4}{c}{ Metal ion content(mg/kg) } \\
& $\mathrm{Cd}$ & $\mathrm{Mg}$ & $\mathrm{Ca}$ & $\mathrm{Mn}$ & $\mathrm{Fe}$ & $\mathrm{Cu}$ & $\mathrm{Zn}$ \\
$\begin{array}{l}\text { Blue S. uncinata } \\
\text { leaves }\end{array}$ & $0.04 \pm 0.01 \mathrm{~B}$ & $4311.71 \pm 340.96 \mathrm{~B}$ & $598.88 \pm 41.69 \mathrm{~A}$ & $115.12 \pm 8.63 \mathrm{~A}$ & $421.11 \pm 22.45 \mathrm{~B}$ & $8.62 \pm 0.63 \mathrm{~B}$ & $55.04 \pm 4.30 \mathrm{~A}$ & $592.45 \pm 14.47 \mathrm{~B}$ \\
$\begin{array}{l}\text { Red S. uncinata } \\
\text { leaves }\end{array}$ & $0.03 \pm 0.00 \mathrm{~A}$ & $8134.86 \pm 227.00 \mathrm{C}$ & $919.65 \pm 23.63 \mathrm{~B}$ & $139.09 \pm 3.70 \mathrm{~B}$ & $308.02 \pm 8.97 \mathrm{~A}$ & $5.61 \pm 1.23 \mathrm{~A}$ & $58.00 \pm 3.26 \mathrm{~A}$ & $316.21 \pm 8.44 \mathrm{~A}$ \\
$\begin{array}{l}\text { S. kraussiana } \\
\text { leaves }\end{array}$ & $0.04 \pm 0.00 \mathrm{AB}$ & $3464.87 \pm 77.35 \mathrm{~A}$ & $1152.27 \pm 19.28 \mathrm{C}$ & $386.18 \pm 10.13 \mathrm{C}$ & $583.86 \pm 7.83 \mathrm{C}$ & $6.20 \pm 0.61 \mathrm{~A}$ & $117.93 \pm 1.69 \mathrm{~B}$ & $806.34 \pm 4.39 \mathrm{C}$ \\
\hline
\end{tabular}

Note: metal ion content $=$ mean value \pm standard deviation $(n=3) ; \mathrm{A}, \mathrm{B}$, and $\mathrm{C}$ show the different significant differences at $P=0.05$ level in SNK test.
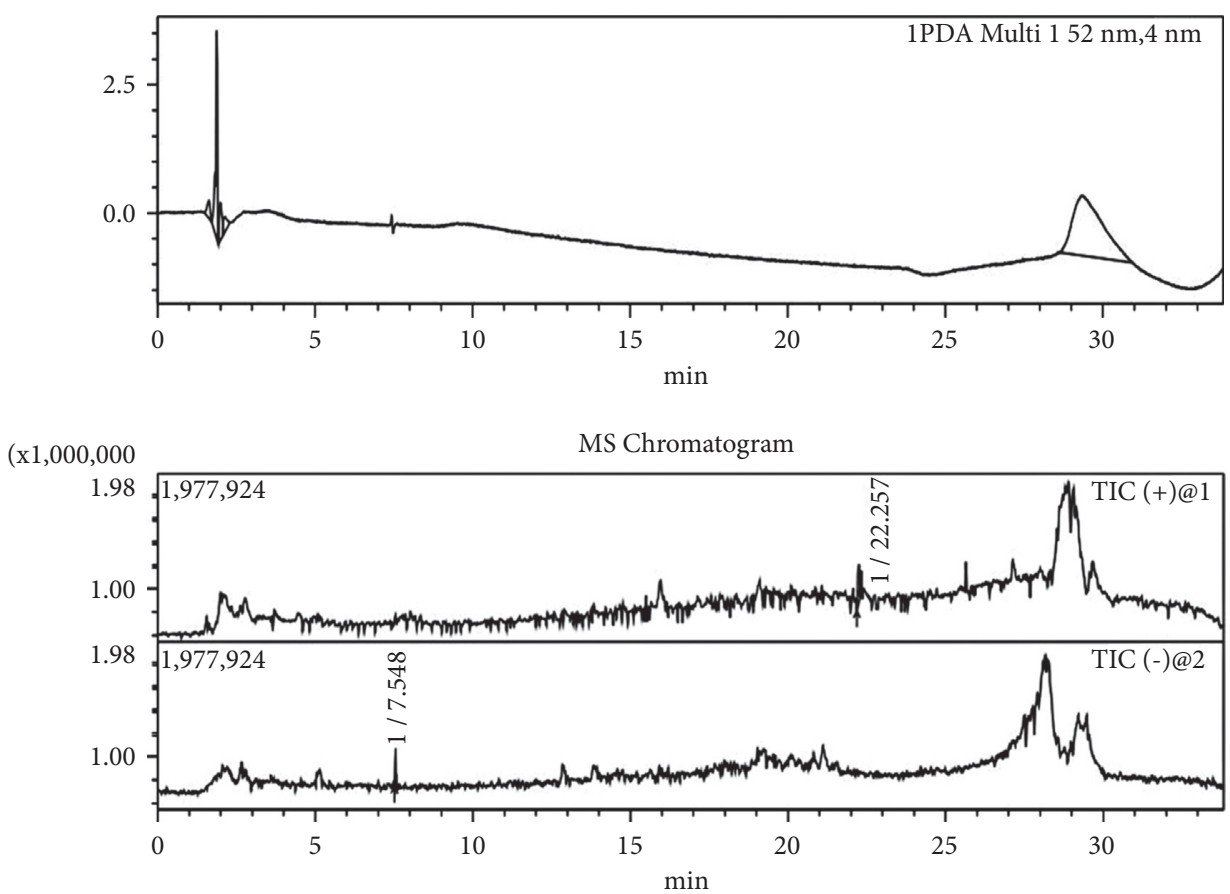

Figure 4: Chromatogram $(520 \mathrm{~nm})$ and total ion flow diagrams for anthocyanin extracting solution in blue S. uncinata leaves. Note: the peaks near $28 \mathrm{~min}$ are solvent background peaks.

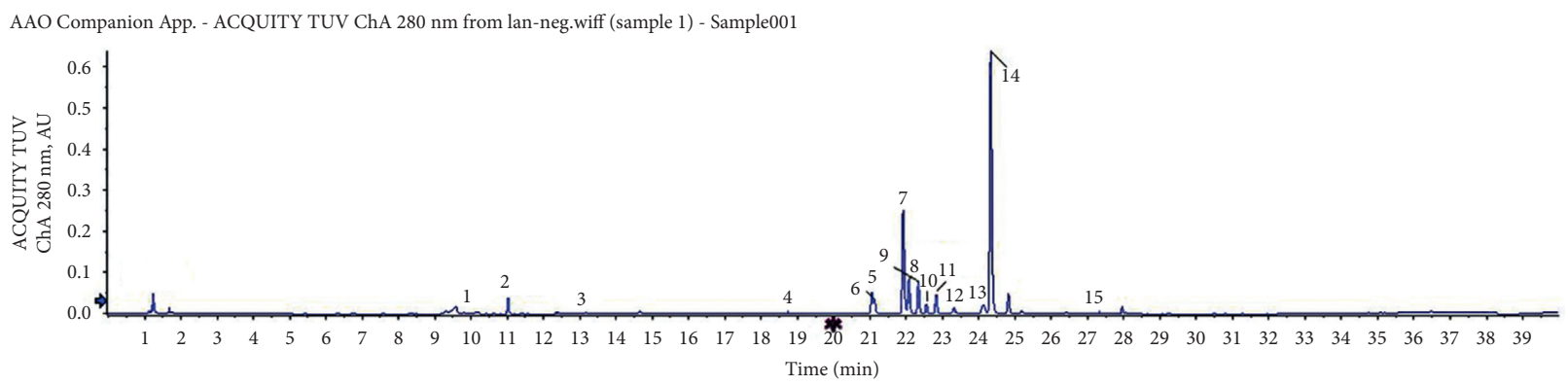

IDA Survey from lan-neg.wiff (sample 1) - Sample001

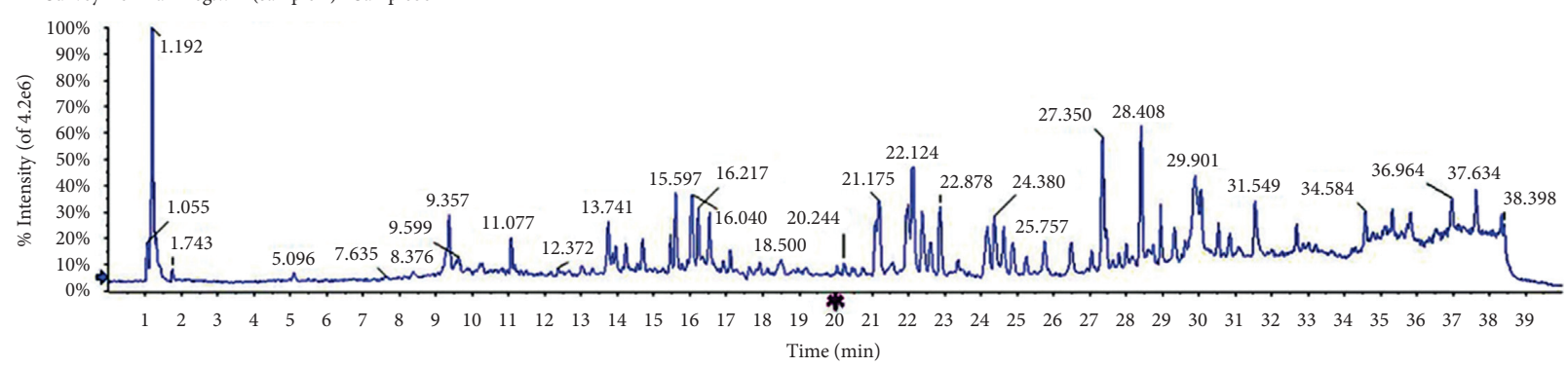

Figure 5: Ultraviolet $(280 \mathrm{~nm})$ chromatogram and total ion flow diagrams of flavonoid extracting solution for blue S. uncinata leaves. 

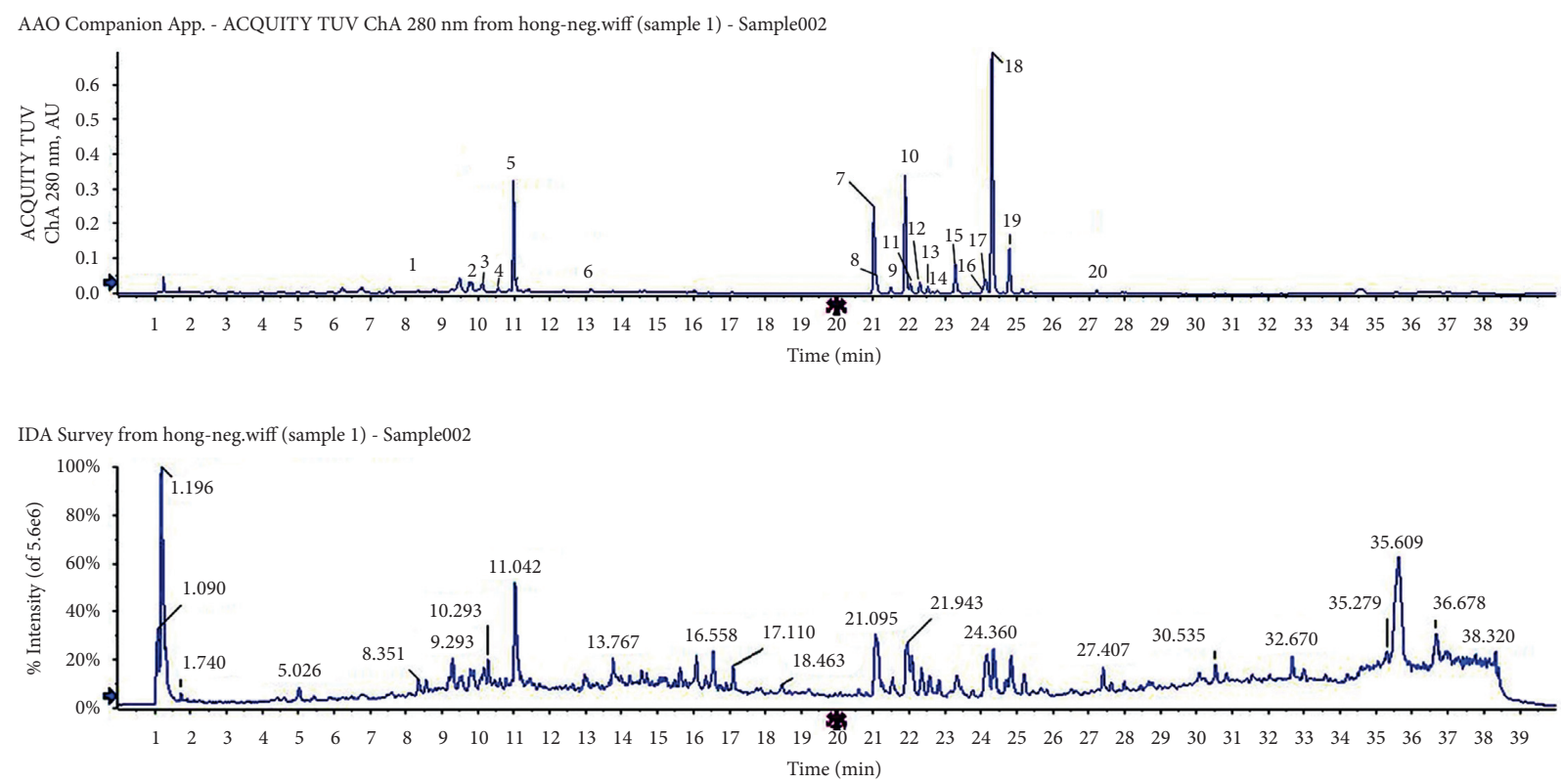

FIGURE 6: Ultraviolet $(280 \mathrm{~nm})$ chromatogram and total ion flow diagrams of flavonoid extracting solution for red $S$. uncinata leaves.
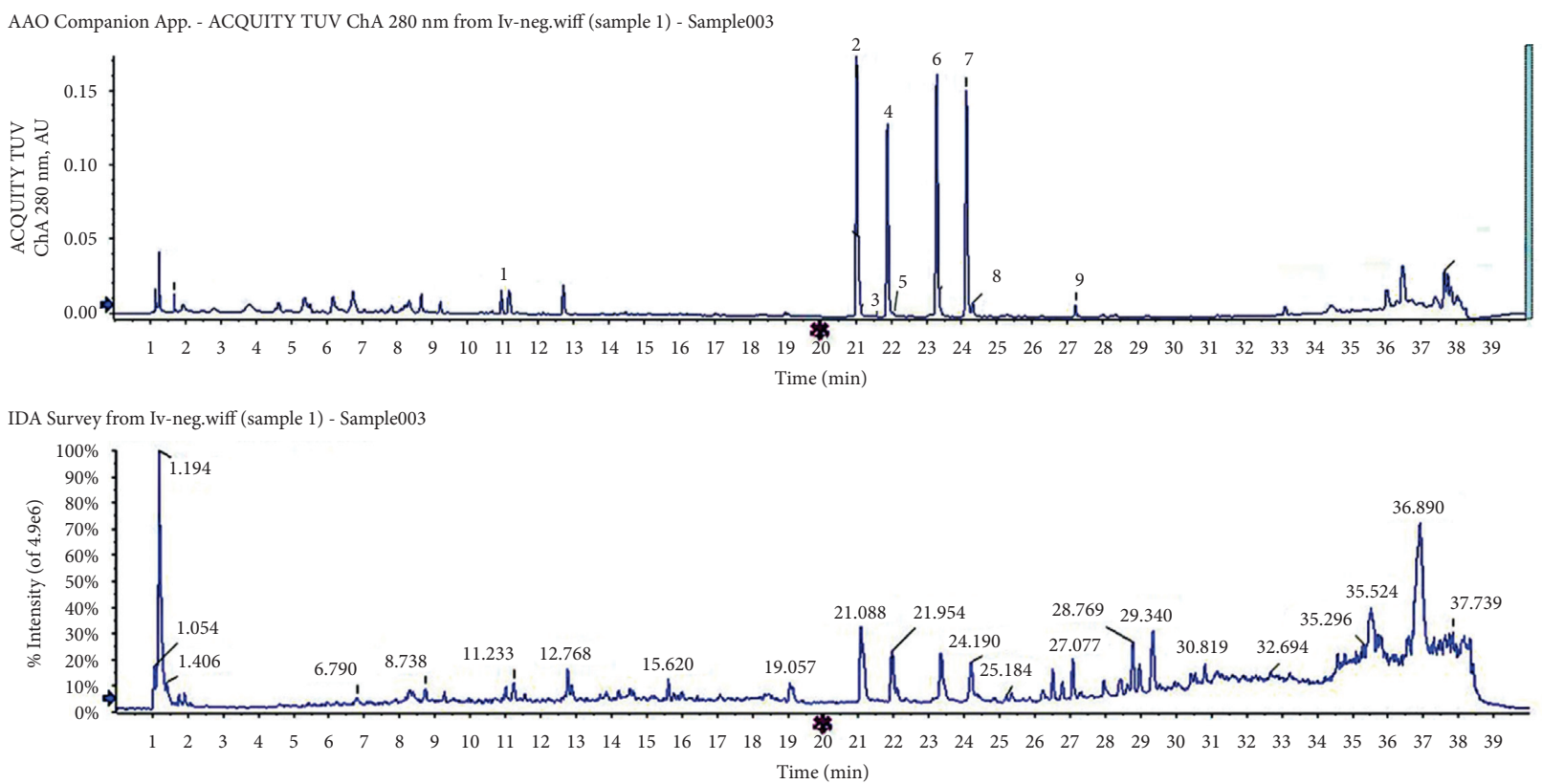

Figure 7: Ultraviolet $(280 \mathrm{~nm})$ chromatogram and total ion flow diagrams of flavonoid extracting solution for S. kraussiana leaves.

conducive to pigment, whereas flat epidermal cells decreased the effect, making their color appear lighter.

By comparing leaf paraffin transverse sections, freehand sections, and SEM photomicrographs, we found that the shape of the adaxial epidermis of $S$. uncinata leaves was not only different from the abaxial epidermis, but also different from the adaxial epidermis of $S$. kraussiana. The shape appeared convex or lens-shaped on the lateral view and irregular circles with smooth embossment on the top view. This result corresponds with those of Hébant and Lee [1], who examined the convexly curved upper epidermal cells of $S$. willdenowii by SEM. The structure increases the proportion of incident light entering the cell, deepens the leaf color $[40,43]$, and therefore may be related to blue leaf coloration.

According to Hébant and Lee [1], the blue color of S. uncinata results from thin-film interference. Which contributes more to blue coloration? Is it thin-film interference or convex or lens-shaped epidermal cells? Do they work complementary? It needs more intensive research.

4.3. Effects of the $p H$ on Blue Coloration in S. uncinata. The color of plant leaves is affected to some extent by the $\mathrm{pH}$ within vacuoles, which has a great influence on the coloration of anthocyanins, with varying performance among 


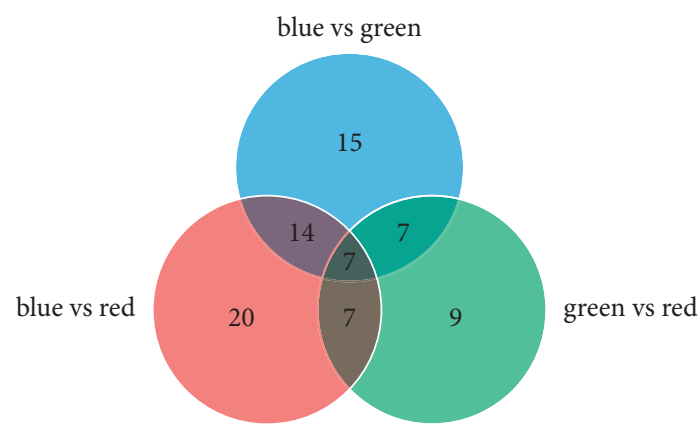

Figure 8: Venn diagram of flavonoids in the three leaf types.

different plant species. Tang et al. [44] found that the $\mathrm{pH}$ affected anthocyanin synthesis and stability. The degradation rate of anthocyanins has been accelerated by increasing the $\mathrm{pH}$ during the process of red turning green in Loropetalum chinense var. rubrum. Studies on the relationship between leaf pigment content and leaf color change in Liquidambar formosana have shown that a reduction in $\mathrm{pH}$ was one reason their leaves turned red [45]. Research by Shi [46] indicated that Prunus cerasifera leaf color appeared red in a medium with $\mathrm{pH}<5$, and the stronger the acidity, the more red the pigment. Red color was stable when the $\mathrm{pH}$ ranged from 4 to 5 , and the solution turned green at $\mathrm{pH}>5$. The stronger the alkalinity, the more green the pigment. Most research results have indicated that anthocyanins present stable red when the $\mathrm{pH}$ of the vacuole is lower, and unstable blue occurs as the $\mathrm{pH}$ increases.

The vacuole is the largest organelle in the mature leaf cell. The $\mathrm{pH}$ of leaf juice is often used to approximate the $\mathrm{pH}$ of the vacuole [47]. We used this method in our experiment, with results indicating that the $\mathrm{pH}$ of blue leaves was greater than that of red leaves. This result is consistent with previous results that the $\mathrm{pH}$ of blue flowers was greater than that of red flowers, in Hydrangea macrophylla [48] and Pharbitis nil (Linn.) Choisy [22]. However, for the specific value, the difference between the two $\mathrm{pH}$ values was only 0.08 , and the difference between those of blue $S$. uncinata leaves and S. kraussiana leaves is only 0.11 , whereas that between blue and red cultivars of $H$. macrophylla was 0.8 [48] and that between blue in the full-bloom stage and red in the burgeoning stage of P. nil (Linn.) Choisy was 1.1 [22]. Therefore, we conclude that blue leaf coloration in S. uncinata has no concern with alkalization of the $\mathrm{pH}$ in the vacuole.

\subsection{Effects of Metal Ion Content on Blue Coloration in S. uncinata}

4.4.1. Effects of Metal Ion Content on Anthocyanin Coloration. Anthocyanins can be combined with metal ions and flavonoids in a stoichiometric ratio or not, to be assembled into metal pigment complexes [49], and these complexes can affect the coloration of plant leaves. There have been several studies of metal anthocyanins making color tend toward bluish, and these concentrate primarily on $\mathrm{Mg}, \mathrm{Al}, \mathrm{Fe}$ [23-25, 48, 50], Ca [30], and Mn [30]. Metal ions have a stable and protective effect on anthocyanins, and the pigments are often chelated if the cell sap contains metal ions such as $\mathrm{Al}, \mathrm{Fe}, \mathrm{Mg}$, or Mo. In particular, anthocyanins, which change their color to some degree, often tend toward purple after chelation [51].

In our experiment, $\mathrm{Mg}, \mathrm{Ca}, \mathrm{Mn}, \mathrm{Fe}, \mathrm{Zn}$, and $\mathrm{Al}$ ion contents were all relatively high in the three leaf types; however, there was no anthocyanin in blue $S$. uncinata leaves, so we concluded that blue leaf coloration in $S$. uncinata was unrelated to metal chelation with anthocyanin.

4.4.2. Effects of Metal Ion Content on Chlorophyll. Metal ions insert protoporphyrin IX, which is the branching point of chlorophyll synthesis and heme and plant pigment synthesis, $\mathrm{Mg}$ ions under the catalysis of a $\mathrm{Mg}$ ion chelating enzyme (CHLH) insert protoporphyrin IX, forming the chlorophyll branch; Fe ions under the catalysis of a Fe ion chelating enzyme (FECH) insert protoporphyrin IX, forming the heme and plant pigment branch. At the branch point, $\mathrm{CHLH}$ and FECH complete protoporphyrin IX [52].

$\mathrm{Mg}$ is a part of the molecular composition of chlorophyll; chlorophyll formation will be affected if it is lacking. The concentration of $\mathrm{Mg}^{2+}$ influences the activity of CHLH [53]. $\mathrm{Fe}$ is necessary for protochlorophyllide formation; $\mathrm{Mg}$ protoporphyrin IX and Mg-protoporphyrin IX methyl ester accumulate when short of $\mathrm{Fe}$, and protochlorophyllide cannot form chlorophyll $[53,54]$. Chlorophyll synthesis is also affected by the content of $\mathrm{Cu}, \mathrm{Mn}$, and other ions.

In our experiment, the $\mathrm{Cu}$ content was not high, but those of $\mathrm{Mg}, \mathrm{Fe}$, and $\mathrm{Mn}$ were very high, particularly that of $\mathrm{Mg}$, with content reaching $4311.7 \mathrm{mg} / \mathrm{kg}$, which was $1.24-$ fold higher in blue leaves than in red leaves. We speculate that such high Mg levels may be associated with chlorophyll synthesis in S. uncinata.

\subsection{Effects of Anthocyanin and Copigment on Blue Coloration} in S. uncinata. Copigments, often flavone and flavonols, are the two branches of the flavonoid metabolic pathway [55]. Combined with anthocyanins, they can stabilize pigments, and the compounds they form will influence the coloration of anthocyanins to some degree [56]. Research by Li [57] found that the effect of copigments turned purple or pink delphinidin flowers blue. Malvidin-3-glucoside is the basic anthocyanin of Primula sinensis; the flower appears purple when it is combined with flavonol, but appears garnet when not combined [58]. Under certain conditions, the larger the molar ratio of flavonols and anthocyanins, the more significant the copigmentation effect.

In our research, we detected anthocyanins in a preliminary experiment by measuring absorbance values using an enzyme-linked immunosorbent assay (ELISA). Although the overall content was low, and the highest content was only 1.2 pigment units [14], we still initially speculate that blue leaf coloration in $S$. uncinata may be related to delphinidin in anthocyanins, or a copigment with anthocyanins. We did not detect anthocyanins in blue leaves using liquid chromatography-MS (this is accordant with the conclusion that compared with the anthocyanin biosynthesis pathway, the chlorophyll metabolism pathway may be the primary pigment metabolism pathway of $S$. uncinata [15], although 


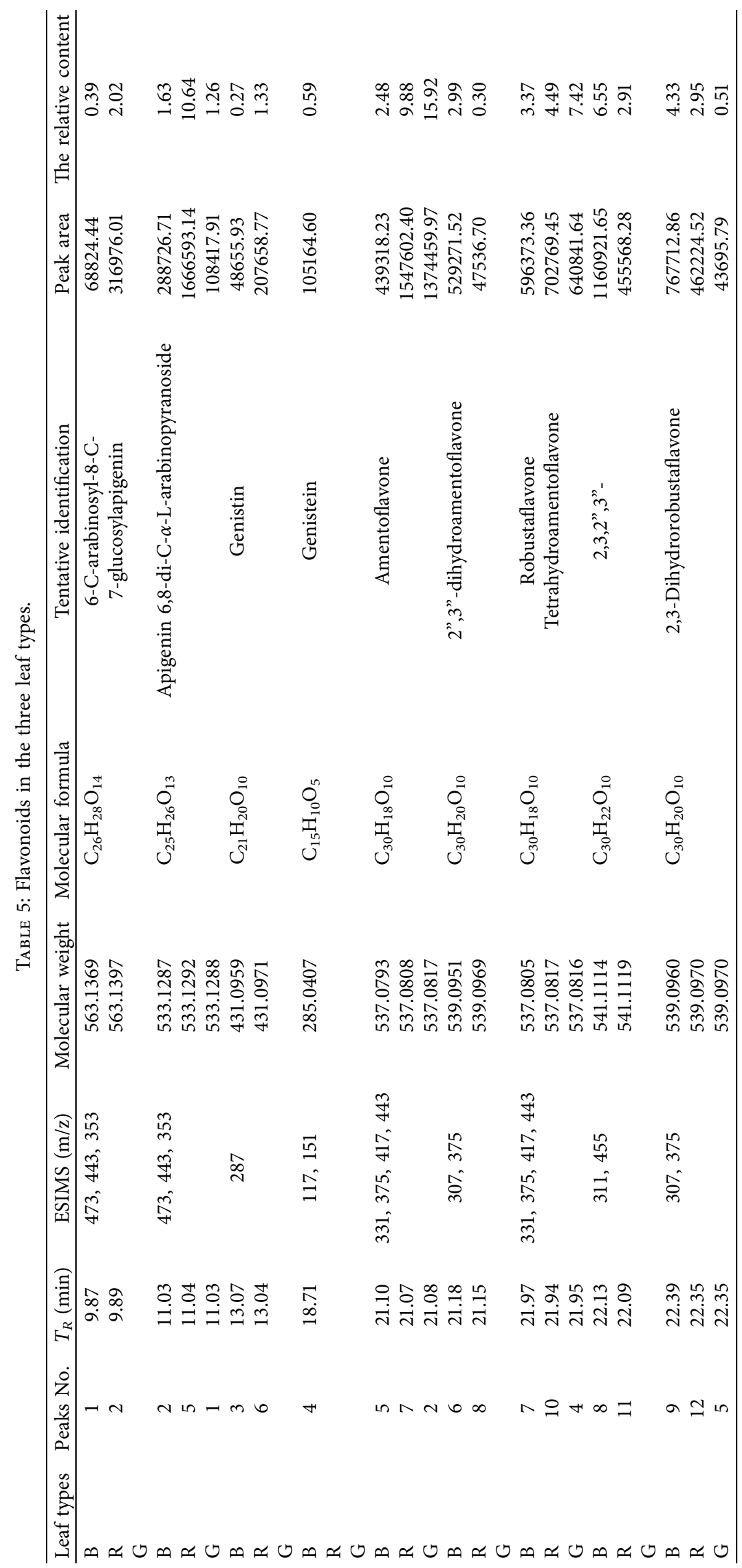




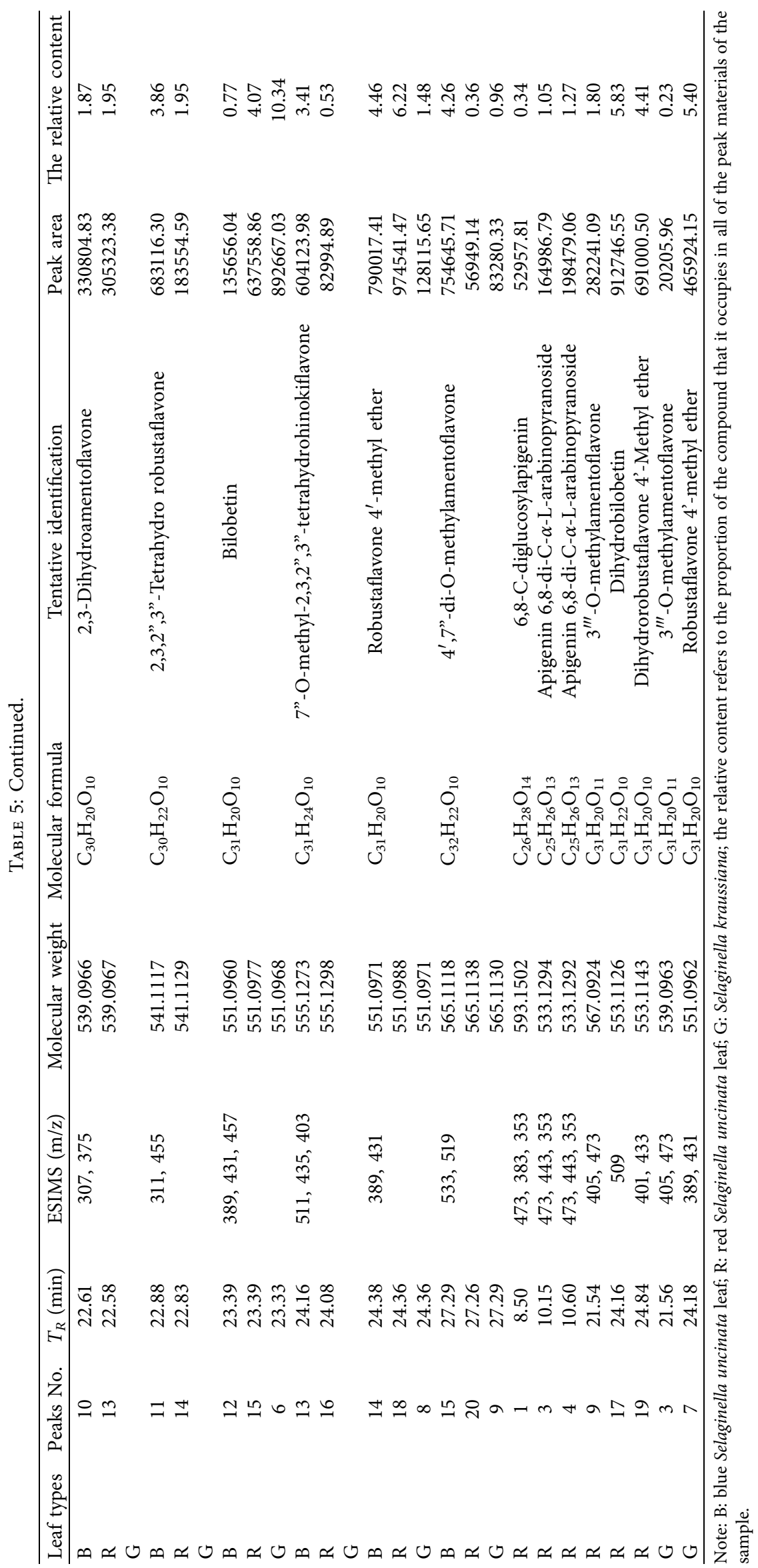


there were copigments such as flavone). If anthocyanins are not present, the copigmentation of flavone cannot occur. Therefore, we infer that blue leaf coloration in S. uncinata was not caused by copigmentation of anthocyanins.

\section{Conclusion}

Through comparison of leaf paraffin transverse sections, freehand sections, and SEM photomicrographs, we found that the shape of the adaxial epidermis of S. uncinata leaves was convex or lens-shaped on the lateral view and irregular circles with smooth embossment on the top view. These shapes were different from those on the abaxial epidermis and the adaxial epidermis of $S$. kraussiana leaves. We speculated these structures increase the proportion of incident light entering the cell, deepening the leaf color, and therefore may be related to blue leaf coloration.

Through comparison of previously published values of leaf $\mathrm{pH}$ and metal ion content, anthocyanins, and flavonoids with those of the three leaf types in our study, we found that leaf $\mathrm{pH}$ was similar among the leaf types and that the leaves all contained high levels of metal ions such as $\mathrm{Mg}, \mathrm{Fe}, \mathrm{Mn}$, and copigments such as flavones. However, because there was no anthocyanin present in blue $S$. uncinata leaves, we conclude that blue leaf coloration in S. uncinata was not related to the three hypotheses of blue coloration: alkalization of vacuole $\mathrm{pH}$, metal chelation, and copigmentation with anthocyanins.

\section{Data Availability}

The raw data supporting the conclusions of this article will be made available by the authors, without undue reservation.

\section{Conflicts of Interest}

The authors declared that they have no conflicts of interest regarding this work.

\section{Authors' Contributions}

Lin Li wrote the manuscript. Rongyan Deng designed the research. Lulu Yang helped produce several figures and processed data. Aihua Qin, Fangyi Jiang, and Limei Chen conducted the experiment. All authors read and approved the manuscript.

\section{Acknowledgments}

The authors gratefully thank the assistance of Liqiong Zhu and Weixin Jiang in analyzing data. This work was supported by the National Natural Science Foundation of China (31960613) and the open project of the South China FastGrowing Wood Breeding Laboratory of the National Forestry Administration (KF (2018)-01).

\section{References}

[1] C. Hebant and D. W. Lee, "Ultrastructural basis and developmental control of blue iridescence in Selaginella leaves," American Journal of Botany, vol. 71, no. 2, pp. 216-219, 1984.
[2] R. Imaichi and M. Kato, "Developmental anatomy of the shoot apical cell, rhizophore and root ofSelaginella uncinata," Botanical Magazine Tokyo, vol. 102, no. 3, pp. 369-380, 1989.

[3] M. Takamiya, "Comparative karyomorphology and interrelationships ofSelaginella in Japan," Journal of Plant Research, vol. 106, no. 2, pp. 149-166, 1993.

[4] B. Oldenkott, K. Yamaguchi, S. Tsuji-Tsukinoki, N. Knie, and V. Knoop, "Chloroplast RNA editing going extreme: more than 3400 events of C-to-U editing in the chloroplast transcriptome of the lycophyte Selaginella uncinata," $R N A$, vol. 20, no. 10, pp. 1499-1506, 2014.

[5] D. R. Smith, "Unparalleled GC content in the plastid DNA of Selaginella," Plant Molecular Biology, vol. 71, no. 6, pp. 627-639, 2009.

[6] S. Tsuji, K. Ueda, T. Nishiyama et al., "The chloroplast genome from a lycophyte (microphyllophyte), Selaginella uncinata, has a unique inversion, transpositions and many gene losses," Journal of Plant Research, vol. 120, no. 2, pp. 281-290, 2007.

[7] J.-X. Zheng, N.-L. Wang, H.-W. Liu et al., "Four new biflavonoids from Selaginella uncinata and their anti-anoxic effect," Journal of Asian Natural Products Research, vol. 10, no. 10, pp. 945-952, 2008.

[8] J. X. Zheng, Y. Zheng, and Q. P. Yan, "Study on the extraction technology of total flavonoids from Selaginella uncinata," Journal of Chinese Medicinal Materials, vol. 34, no. 12, pp. 1940-1942, 2011.

[9] J. X. Zheng, Y. Zheng, H. Zhi et al., "New $3^{\prime}, 8^{\prime \prime}$-linked biflavonoids from Selaginella uncinata displaying protective effect against anoxia," Molecules, vol. 16, no. 8, pp. 6206-6214, 2011.

[10] J.-X. Zheng, Y. Zheng, H. Zhi et al., " $\gamma$-Lactone derivatives and terpenoids from Selaginella uncinata and their protective effect against anoxia," Chemistry of Natural Compounds, vol. 50, no. 2, pp. 366-369, 2014.

[11] J. Zheng, Y. Zheng, H. Zhi et al., "Two new steroidal saponins from Selaginella uncinata (Desv.) Spring and their protective effect against anoxia," Fitoterapia, vol. 88, pp. 25-30, 2013.

[12] H. Zou, K.-P. Xu, F.-S. Li et al., "Uncinataflavone, a new flavonoid with a methyl benzoate substituent fromSelaginella uncinata," Journal of Asian Natural Products Research, vol. 15, no. 4, pp. 408-412, 2013.

[13] H. Zou, K.-P. Xu, Z.-X. Zou et al., "A new flavonoid with 6phenyl substituent from Selaginella uncinata," Journal of Asian Natural Products Research, vol. 15, no. 1, pp. 84-88, 2013.

[14] L. Li, J. Huang, and S. Zhang, "Effect on different shade treatments of leaf color change of Selaginella uncinata," Molecular Plant Breeding, vol. 13, no. 5, pp. 1135-1140, 2015.

[15] L. Li, Q. Wang, and R. Deng, "Transcriptome profiling of blue leaf coloration in Selaginella uncinata," Canadian Journal of Plant Science, vol. 97, no. 4, pp. 580-593, 2016.

[16] B. J. Glover and H. M. Whitney, "Structural colour and iridescence in plants: the poorly studied relations of pigment colour," Annals of Botany, vol. 105, no. 4, pp. 505-511, 2010.

[17] R. M. Graham, D. W. Lee, and K. Norstog, "Physical and ultrastructural basis of blue leaf iridescence in two neotropical ferns," American Journal of Botany, vol. 80, no. 2, pp. 198-203, 1993.

[18] K. S. Gould and D. W. Lee, "Physical and ultrastructural basis of blue leaf iridescence in four Malaysian understory plants," American Journal of Botany, vol. 83, no. 1, pp. 45-50, 1996.

[19] D. W. Lee, "Ultrastructural basis and function of iridescent blue colour of fruits inElaeocarpus," Nature, vol. 349, no. 6306, pp. 260-262, 1991. 
[20] R. Willst Tter and A. E. Everest, "Untersuchungen über die Anthocyane. I. Über den Farbstoff der Kornblume," Justus Liebigs Annalen der Chemie, vol. 401, pp. 189-232, 1913.

[21] R. Willst Tter and H. Mallison, "Untersuchungen über die Anthocyane. X. Über Variationen der Blütenfarben," Justus Liebigs Annalen der Chemie, vol. 408, no. 1, pp. 147-162, 1915.

[22] K. Yoshida, T. Kondo, Y. Okazaki, and K. Katou, "Cause of blue petal colour,” Nature, vol. 373, no. 6512, p. 291, 1995.

[23] K. Momonoi, K. Yoshida, S. Mano et al., "A vacuolar iron transporter in tulip, TgVit1, is responsible for blue coloration in petal cells through iron accumulation," The Plant Journal, vol. 59, no. 3, pp. 437-447, 2009.

[24] T. Kondo, Y. Toyama-Kato, and K. Yoshida, "Essential structure of co-pigment for blue sepal-color development of hydrangea," Tetrahedron Letters, vol. 46, no. 39, pp. 6645-6649, 2005.

[25] Y. Toyama-Kato, T. Kondo, and K. Yoshida, "Synthesis of designed acylquinic acid derivatives involved in blue color development of hydrangea and their co-pigmentation effect," Heterocycles, vol. 72, pp. 239-254, 2007.

[26] Z. L. Li, Plant Organization SectionPeking University Press, Beijing, China, 1996.

[27] L. Q. Zhu, Y. Wang, and L. J. Zhao, "Quantitative analysis on leaf anatomical structures and their stress resistance of eight Ficus species," Guangxi Sciences, vol. 19, no. 1, pp. 88-92, 2012.

[28] Y. Xiao, W. Liu, and Y. Wang, "The drying method of scanning electron microscopy in biological samples [J]," Laboratory research and exploration, vol. 32, no. 5, pp. 45-53, 2013.

[29] W. B. Zhou and B. S. Qiu, "The measurement of $\mathrm{pH}$ value in plant cell," Plant Physiology Journal, vol. 40, no. 6, pp. 724728, 2004.

[30] H. B. Li, The Effect of Anthocyanidin, Metal Elements and $p H$ on the Colour Formation of Blue Flowers from MonocotsDissertation, Northwest Agriculture \& Forestry University, Yangling, China, 2013.

[31] A. Liu, Q. Wang, and Y. U. Gang, "Flower color and anthocyanins of lupinus polyphyllus," Acta Agriculturae BorealiOccidentalis Sinica, vol. 21, no. 3, pp. 164-169, 2012.

[32] M. Yi, X. Sheng, and K. Xu, "Flavonoids from Selaginella uncinata," Zhongguo Zhong yao za zhi= Zhongguo zhongyao zazhi = China journal of Chinese materia medica, vol. 40, no. 15 , pp. 3005-3008, 2015.

[33] X. L. Fan, J. C. Xu, and X. H. Lin, "Study on biflavonoids from Selaginella uncinata (desv.) spring," Journal of Chinese Pharmaceutical Sciences, vol. 44, no. 1, pp. 15-19, 2009.

[34] X. Q. Wu, H. Zou, and G. S. Tan, "Chemical constituents of Selaginella uncinata(desv.) spring," Central South Pharmacy, vol. 08, pp. 817-819, 2016.

[35] Z. H. Zhang and X. Wu, "Study on the anatomy structure of five species of fern leaves and its adaptability to sciophyte environment," Journal of Huazhong Normal University, vol. 47, no. 6, pp. 840-843, 2013.

[36] M. D. Abrams and M. E. Kubiske, "Leaf structural characteristics of 31 hardwood and conifer tree species in central Wisconsin: influence of light regime and shade-tolerance rank," Forest Ecology and Management, vol. 31, no. 4, pp. 245-253, 1990.

[37] J. Zhong, Study on Leaf Morphological Structrue and Pigment of Ornamental Plant-Ardisia MamillataDissertation, Sichuan Agricultural University, Chengdu, China, 2008.

[38] R. Ghaffar, M. Weidinger, B. Mähnert, M. Schagerl, and I. Lichtscheidl, "Adaptive responses of mature giant chloroplasts in the deep-shade lycopodSelaginella erythropusto prolonged light and dark periods," Plant, Cell and Environment, vol. 41, no. 8, pp. 1791-1805, 2018.

[39] C.-R. Sheue, V. Sarafis, R. Kiew et al., "Bizonoplast, a unique chloroplast in the epidermal cells of microphylls in the shade plant Selaginella erythropus (Selaginellaceae)," American Journal of Botany, vol. 94, no. 12, pp. 1922-1929, 2007.

[40] K.-i. Noda, B. J. Glover, P. Linstead, and C. Martin, "Flower colour intensity depends on specialized cell shape controlled by a Myb-related transcription factor," Nature, vol. 369, no. 6482, pp. 661-664, 1994.

[41] A. Quintana, J. Albrechtová, R. J. Griesbach, and R. Freyre, "Anatomical and biochemical studies of anthocyanidins in flowers of Anagallis monelli L. (Primulaceae) hybrids," Scientia Horticulturae, vol. 112, no. 4, pp. 413-421, 2007.

[42] R. G. Mudalige, A. R. Kuehnle, and T. D. Amore, "Pigment distribution and epidermal cell shape in Dendrobium species and hybrids," HortScience, vol. 38, no. 4, pp. 573-577, 2003.

[43] J. Yue, Phenotype Observation and Anatomical Structure Research of Petals from the Monocotyledons Blue FlowerDissertation, Northwest Agriculture \& Forestry University, Yangling, china, 2013.

[44] Q. R. Tang, Y. Y. Chen, and P. H. Zhou, "Study on the stability of anthocyanin and $\mathrm{pH}$ changes in cell sap of leaves in Loropetalum chinense var. rubum," Hunan Forestry Science \& Technology, vol. 30, no. 4, pp. 24-25, 2003.

[45] J. Z. Hu and Q. Tian, "Relationship between changes of the pigments content and leaf color changing in Liquidambar formosana," Journal of Northwest Forestry University, vol. 35, no. 10, pp. 219-223, 2007.

[46] B. S. Shi, The Research on the Physiological Characters and the Influence Factors on Leave Color of Purple Leaf Cheey PlumDissertation, Northeast Forestry University, Harbin, China, 2006.

[47] W. Verweij, C. Spelt, G.-P. Di Sansebastiano et al., "An H+ P-ATPase on the tonoplast determines vacuolar $\mathrm{pH}$ and flower colour," Nature Cell Biology, vol. 10, no. 12, pp. 1456-1462, 2008.

[48] K. Yoshida, Y. Toyama-Kato, K. Kameda, and T. Kondo, "Sepal color variation of hydrangea macrophylla and vacuolar $\mathrm{pH}$ measured with a proton-selective microelectrode," Plant and Cell Physiology, vol. 44, no. 3, pp. 262-268, 2003.

[49] T. Kosaku, "Blue metal complex pigments involved in blue flower color," Proceedings of the Japan Academy Series B Physical and Biological Sciences, vol. 82, no. 4, pp. 142-154, 2006.

[50] K. Shoji, N. Miki, N. Nakajima, K. Momonoi, C. Kato, and K. Yoshida, "Perianth bottom-specific blue color development in tulip cv. Murasakizuisho requires ferric ions," Plant and Cell Physiology, vol. 48, no. 2, pp. 243-251, 2006.

[51] Y. L. Li, T. L. Zhao, and L. C. Chen, "Regulation in pigment biosynthesis and color variation of flowers," Chinese Bulletin of Life Sciences, vol. 20, no. 1, pp. 147-152, 2008.

[52] J. E. Cornah, M. J. Terry, and A. G. Smith, "Green or red: what stops the traffic in the tetrapyrrole pathway?" Trends in Plant Science, vol. 8, no. 5, pp. 224-230, 2003.

[53] R. Tanaka and A. Tanaka, "Tetrapyrrole biosynthesis in higher plants," Annual Review of Plant Biology, vol. 58, no. 1, pp. 321-346, 2007.

[54] N. Nagata, R. Tanaka, S. Satoh, and A. Tanaka, "Identification of a vinyl reductase gene for chlorophyll synthesis in Arabidopsis thaliana and implications for the evolution of prochlorococcus species," The Plant Cell Online, vol. 17, no. 1, pp. 233-240, 2005. 
[55] T. Goto and T. Kondo, "Structure and molecular stacking of anthocyanins-flower color variation," Angewandte Chemie International Edition in English, vol. 30, no. 1, pp. 17-33, 1991.

[56] S. J. Bloor, "Blue flower colour derived from flavonol-anthocyanin co-pigmentation in Ceanothus papillosus," Phytochemistry, vol. 45, no. 7, pp. 1399-1405, 1997.

[57] S. W. Li, Ecological Biochemistry, pp. 10-45, Peking University Press, Beijing, China, 2001.

[58] G. Forkmann, "Flavonoids as flower pigments: the Formation of the natural spectrum and its extension by genetic engineering," Plant Breeding, vol. 106, no. 1, pp. 1-26, 1991. 